\title{
HUMAN PAPILLOMAVIRUS AND p53 MUTATIONAL STATUS AS PROGNOSTIC FACTORS IN HEAD AND NECK CARCINOMA
}

\author{
Elizabeth A. Sisk, MD, ${ }^{1}$ Scott G. Soltys, MD, ${ }^{1 \star}$ Shaobo Zhu, MD, ${ }^{1} \dagger$ Susan G. Fisher, PhD, ${ }^{2}$ \\ Thomas E. Carey, PhD, ${ }^{1}$ Carol R. Bradford, MD ${ }^{1}$ \\ ${ }^{1}$ Department of Otolaryngology/Head and Neck Surgery, University of Michigan, 1904 Taubman Center, \\ 1500 East Medical Center Drive, Ann Arbor, Michigan, 48109. E-mail: cbradfor@umich.edu \\ ${ }^{2}$ Department of Community and Preventive Medicine, Division of Epidemiology, University of Rochester, \\ Rochester, New York
}

Accepted 26 March 2002

Published online 24 July 2002 in Wiley InterScience (www.interscience.wiley.com). DOI: 10.1002/hed.10146

\begin{abstract}
Background. Mutations of the p53 tumor-suppressor gene are common in squamous cell carcinoma of the head and neck (SCCHN) and may portend a worse prognosis. Human papillomavirus (HPV) represents another potential prognostic factor for SCCHN. The oncogenic potential of HPV may be due to the ability of its E6 oncoprotein to promote degradation of wild-type p53 protein. We wish to determine whether there is a lower incidence of p53 mutations in HPV-positive versus HPVnegative tumors, and if HPV and/or p53 status has an impact on survival.

Methods. Thirty-two SCCHN specimens were analyzed for mutations of the 053 gene using single-strand conformational polymorphism (SSCP) analysis followed by DNA sequencing. The HPV status of all specimens was evaluated by use of poly-
\end{abstract}

Correspondence to: C. R. Bradford

*Present address: Department of Radiation Oncology, Stanford University, School of Medicine, Palo Alto, California

†Present address: Department of Pathology, Temple University, School of Medicine, Philadelphia, Pennsylvania

Contract grant sponsor: University of Michigan Comprehensive Cancer Center, the Department of Veterans Affairs Medical Center, Ann Arbor, Michigan; the American Academy of Otolaryngology/Head and Neck Surgery Resident Research Training Grant Award; and the National Cancer Institute core grant (P30) CA-46592.

(c) 2002 Wiley Periodicals, Inc. merase chain reaction with HPV consensus primers and Southern blot hybridization. Pertinent clinical information was obtained from chart review.

Results. Nonsilent p53 mutations were present in 2 of 15 (13\%) of HPV-positive tumors compared with 6 of 17 (35\%) of HPV-negative tumors ( $p=.229$; Fisher's exact test, odds ratio .28). A survival advantage was found between HPV-positive compared with HPV-negative specimens $(p=.0264)$ and between 053 wild type compared with p53 mutant specimens ( $p=.01$ ) by univariate log rank analysis. When stratified according to both HPV and p53 status, a statistically significant survival difference was observed largely because of a $100 \%$ survival for the HPV-positive/p53 wild-type group ( $p=.003)$.

Conclusions. This preliminary study supports the notion that the presence of HPV confers a survival advantage among HNSCC patients, particularly when p53 is wild type. (c) 2002 Wiley Periodicals, Inc. Head Neck 24: 841-849, 2002

Keywords: human papillomavirus; p53; squamous cell carcinoma of the head and neck; head and neck carcinoma; survival

It has been well established that tobacco and alcohol use is associated with the development of squamous cell carcinoma of the head and neck (SCCHN). Recent studies have also led many to 
believe that the human papillomavirus (HPV) may play a role in the development of SCCHN. In a review of published reports, McKaig et $\mathrm{al}^{1}$ found the overall prevalence of HPV in head and neck tumors to be $34.5 \%$. The most common tumor site in which HPV was detected was the oral cavity, followed by the pharynx and the larynx. ${ }^{1}$ More recently Gillison et $\mathrm{al}^{2}$ confirmed these findings in a large study of $253 \mathrm{SCCHN}$ tumor samples. They detected HPV DNA in $25 \%$ of specimens, and poor tumor grade and oropharyngeal site independently increased the probability of HPV presence. Schwartz et $\mathrm{al}^{3}$ and Haraf et $\mathrm{al}^{4}$ also found a significant predilection for the tonsillar site. HPV has also been detected in nasopharyngeal carcinomas, ${ }^{5}$ in cell lines derived from a variety of head and neck carcinomas, ${ }^{6}$ and in inverted papillomas that have progressed to SCC. ${ }^{7}$ Precancerous lesions ${ }^{8,9}$ and metastatic lymph nodes ${ }^{10,11}$ have also been shown to contain DNA of the same HPV type as the primary tumor, supporting the involvement of HPV in the development of SCC. Most commonly the "highrisk" HPV types 16 and 18 are involved ${ }^{1}$; however, as many as 14 other types have been isolated from oral lesions. ${ }^{11,12}$

HPV types 16 and 18 are considered "high risk," because their presence is associated with preneoplastic lesions and carcinomas. In contrast, the "low-risk" types, most commonly types 6 and 11, are typically associated with benign proliferative lesions. The oncogenic potential of HPV is thought to be due to two oncoproteins, E6 and E7. The differences in oncogenic potential have been attributed to type-specific differences in the E6 and E7 proteins. ${ }^{13}$ The E6 protein of oncogenic HPV strains has been shown to interact with the p53 protein and promote its degradation by means of an ubiquitin-dependent pathway. ${ }^{13}$ The E7 oncoprotein can, similarly, complex with the retinoblastoma $(\mathrm{Rb})$ protein and inactivate it. ${ }^{14}$ Both p53 and Rb are important tumor-suppressor genes, whose products maintain cell cycle regulation, protect cellular repair processes, and are involved with programmed cell death or apoptosis. One could thus theorize that disruption of these tumor-suppressor proteins by HPV could lead to propagation of mutational changes and cell immortalization.

Because the p53 protein is crucial in maintaining the cell cycle, cellular repair, and apoptosis, it is no surprise that nearly $40 \%$ of all cancer cases diagnosed worldwide contain p53 mutations. ${ }^{15}$ Head and neck cancer is no excep- tion, with roughly $45 \%$ of newly diagnosed cases in 1995 containing p53 mutations. ${ }^{15}$ Previous reports suggest that the presence of a p53 mutation is a poor prognostic marker in advanced laryngeal carcinoma. ${ }^{16}$ This is in contrast to cervical cancer in which the p53 gene is usually wild type in early tumors. ${ }^{17}$ The development of cervical cancer does, however, correlate closely with the presence of high-risk types of HPV. This indicates that inactivation of p53 by the E6 viral protein may be analogous to an inactivating mutation of the p53 gene. ${ }^{17}$

Although HPV has been implicated in the carcinogenesis of SCCHN, it is not entirely analogous to cervical cancer in that many of the tumors do also contain p53 mutations. Gillison et $\mathrm{al}^{2}$ found that HPV-positive tumors were less likely to contain a p53 mutation, but the difference was not statistically significant. However, in the oropharyngeal subset, which contained the most HPV-positive tumors, there was a statistically significant inverse correlation between p53 mutations and the presence of HPV. This study also showed that head and neck cancer patients with HPV-positive tumors have improved survival relative to patients with HPV-negative tumors. ${ }^{2}$ In this study, we wished to observe whether the frequency of p53 mutations differs between the HPV-positive and the HPV-negative groups and to examine the prognostic significance of HPV and p53 status in outcome.

\section{METHODS}

Tumor Specimens. Tumor specimens were obtained from patients with SCCHN diagnosed at the University of Michigan from 1994-1996. Institutional review board approval was obtained from our institution, and all patients completed informed consent documents. Thirty-two specimens were chosen as described in a previous report. ${ }^{18}$ Retrospective chart review was performed to obtain pertinent clinical information, including tobacco and alcohol exposure, tumor stage at the time of diagnosis, outcome, and survival data.

DNA Extraction. Specimens were procured at the time of surgery, immediately snap frozen in liquid nitrogen, and stored at $-70^{\circ} \mathrm{C}$ until the time of DNA extraction. Frozen specimens were serially sectioned with a cryostat at $10-\mu \mathrm{m}$ intervals, with approximately 40 sections used per specimen. The first and last sections were $\mathrm{H} \& \mathrm{E}$ 
stained for histopathologic review. Sections containing less than 70\% SCC cells were enriched by microdissection. DNA extraction was then accomplished using the Nucleon II DNA Extraction Kit (Scotlab, Scotland).

Detection of HPV DNA by PCR. Before performing polymerase chain reaction $(\mathrm{PCR})$ with the primers of interest, control PCR reactions were successfully performed on all samples with $\beta$ globin primers as described ${ }^{19}$ to ensure the presence of amplifiable DNA. All reactions used DNA extracts either from HPV 4 plasmids or Caski cell lines (which contain HPV 16) as a positive control, DNA extracts from "cell line 293" (a known HPV negative line) as a negative control, and distilled water as a reagent control. To prevent contamination among samples, PCR reactions were set up in a physically separated room designated for pre-PCR work only. In addition, pipetters were soaked in a $10 \%$ bleach solution before use and plugged pipet tips were used. Finally, PCR reaction mixtures were irradiated with UV light before addition of sample DNA and Taq DNA polymerase.

Specimens were analyzed by PCR for the presence of HPV DNA using two different consensus primer sets derived from the $\mathrm{E} 1$ open reading frame $(\mathrm{ORF})$ and the $\mathrm{L} 1 \mathrm{ORF}$. PCR with the E1 primer set (IU and IWDO) generates an $850 \mathrm{bp}$ fragment and was performed as described by Gregoire et al. ${ }^{20} \mathrm{PCR}$ with the L1 primers generates a $600 \mathrm{bp}$ fragment and was performed as described by Shamanin et $\mathrm{al}^{21}$ using two pairs of degenerate consensus primers ("A" and " $\mathrm{C}$ "; and "B" and "C"). The details of both the E1 primer and L1 primer PCR reactions were thoroughly reported previously. ${ }^{18}$

Southern Blot Hybridization and HPV Typing. Southern blot hybridization was carried out on all PCR products as previously described. ${ }^{18}$ Samples that were positive for HPV DNA after PCR and Southern blot hybridization were typed with oligonucleotide probes derived from the E1 region, as well as repeating PCR with HPV 16-type specific primers as we have described. ${ }^{18,22}$

p53 Mutational Analysis. Exons 5 through 8 of the p53 gene were analyzed for mutations by singlestrand conformational polymorphism (SSCP) analysis. Exons 5 through 8 were amplified by polymerase chain reaction (PCR) using the prim- ers as described by Fujita et al. ${ }^{23}$ The PCR mixture $(10 \mu \mathrm{L}$ total) contained genomic DNA (approximately $100 \mathrm{ng}$ ), 1X PCR reaction buffer (Promega, Madison, WI), 1.5-mmol/L magnesium chloride, $80-\mu \mathrm{mol} / \mathrm{L}$ each deoxyribonucleoside triphosphate, $0.3-\mu \mathrm{mol} / \mathrm{L}$ each of $5^{\prime}$ and $3^{\prime}$ primer, 1 $\mu \mathrm{Ci}$ of $\left[\alpha-{ }^{32} \mathrm{P}\right]$ deoxycytidine triphosphate, and 0.25 U of Taq polymerase (Promega, Madison, WI). The PCR mixture was heated to $95^{\circ} \mathrm{C}$ for 5 minutes followed by 30 thermal cycles. Each cycle included 40 seconds of denaturing at $95^{\circ} \mathrm{C}, 40$ seconds of primer annealing at $58^{\circ} \mathrm{C}$, and 50 seconds of extension and synthesis at $72^{\circ} \mathrm{C}$. The 30 cycles were followed by additional 7 minutes of extension at $72^{\circ} \mathrm{C}$ and chilling at $4{ }^{\circ} \mathrm{C}$. All reactions were run with a cell line known to be p53 wild type as a negative control and water as a reagent control.

To optimize detection of mutations, SSCP was performed at room temperature and $-4^{\circ} \mathrm{C}$ (gels were run in a cold room kept at $-4^{\circ} \mathrm{C}$ ). For room temperature SSCP, gels were composed of 5\% glycerol, 0.6X MDE gel (FMC, Rockland, ME), and $0.6 \mathrm{X}$ tris borate ethylenediaminetetraacetic acid (TBE). For the $-4^{\circ} \mathrm{C}$ SSCP, gels were composed of $12 \%$ nondenaturing polyacrylamide and 1X TBE. Five microliters of PCR product was diluted in $45 \mu \mathrm{L}$ of loading buffer $(10 \mathrm{mmol} / \mathrm{L}$ sodium hydroxide, $95 \%$ formamide, $0.05 \%$ bromophenol blue, $0.05 \%$ xylene cyanol) and heat denatured at $95^{\circ} \mathrm{C}$ for 5 minutes followed immediately by chilling on ice. Five microliters of this mixture was immediately loaded onto the gel and run at constant power of 4 to $6 \mathrm{~W}$ for 15-18 hours at either room temperature or at $-4^{\circ} \mathrm{C}$. The gels were vacuum dried and exposed to films (Kodak $\mathrm{X}$-Omat) at room temperature for 1-2 days.

PCR-amplified DNA fragments that showed bands with altered mobility by SSCP analysis were further analyzed by sequencing. All mutations that were identified by sequencing of cloned PCR products were confirmed in a second, independent PCR reaction. PCR reactions were performed as described and run on 3\% agarose gels to confirm amplification of correct target sequences. PCR-amplified DNA fragments were ligated into pCRII vector (Invitrogen, San Diego, CA) overnight at $14^{\circ} \mathrm{C}$. Ligated DNA was then used to transform INV $\alpha \mathrm{F}^{\prime}$-competent cells (Invitrogen). Cells were plated on X-Gal, ampicillin agar plates and incubated overnight at $37^{\circ} \mathrm{C}$. Several white colonies were picked from each reaction and grown in LB medium. Plasmid DNA was harvested and sequenced (University of Michigan DNA Sequencing Core) using M13 for- 
ward and reverse primers. Mutations observed by automated sequencing were confirmed by manual sequencing (Sequenase 2.0, USB, Cleveland, $\mathrm{OH})$. A minimum of five individual clones was sequenced for each specimen.

Statistical Analysis. Associations among the categorical variables, including HPV status, presence of p53 mutations, tobacco and alcohol use, tumor site, and stage of disease, were explored using Fisher's exact test and the chi-square test. Two-sided alpha levels of less than .05 were considered statistically significant. Kaplan-Meier survival techniques were used to estimate the actuarial survival of subjects stratified by both HPV and p53 status. Survival was calculated from the date of diagnosis to the date of death; surviving subjects were censored at the date last known alive. Differences among the four groups were compared by the log rank test; as with previous analyses, a two-sided alpha level of $<.05$ was considered statistically significant.

\section{RESULTS}

Specimens from 32 patients diagnosed with SCCHN were analyzed for the presence of HPV DNA and for the presence of p53 mutations. Characteristics of these patients have previously been described. ${ }^{18}$ Most patients were exposed to known HNC carcinogens, including $84 \%$ with a history of tobacco use, $48 \%$ with frequent alcohol consumption, and 39\% with occasional alcohol consumption. Tumors were of various sites, including 22 oral cavity or oropharyngeal tumors, 9 laryngeal tumors, and 1 hypopharyngeal tumor. Most tumors were at a late stage at the time of presentation, with $91 \%$ of tumors at stage III or IV. Follow-up ranged from 6 to 50 months, with an average of 23.2 months, and at the time of last contact 17 patients had no evidence of disease, 4 were alive with their disease, and 11 were dead of their disease.

The overall prevalence of HPV DNA detected in the samples was $46.9 \%$ (15 of 32). The concordance between the two primer sets was $87.5 \%$. Six of 15 (40\%) HPV-positive samples did not exhibit a visible band when PCR products were run on ethidium bromide-stained gels. These were only detected after Southern blot hybridization of PCR products. This high percentage indicates that HPV is often present in very low copy numbers in SCCHN.
Overall $60 \%$ (9 of 15 ) of the positive samples were HPV type $16,6.6 \%$ ( 1 of 15 ) were HPV type 18 , and $33.3 \%$ (5 of 15 ) remain untyped. All positive samples were hybridized with HPV typespecific oligonucleotide probes derived from the E1 region. Eight of the 15 positive samples were found to be HPV type 16, and 1 of 15 positive samples was found to be HPV type 18 by this method. One additional sample was characterized as type 16 after repeating PCR and Southern blot hybridization with primers and oligoprobe derived from the E6 ORF. ${ }^{22}$ The remaining five samples remained untyped despite these methods and despite multiple attempts to clone and sequence the HPV DNA. Of note is that all five untyped samples were found to be positive for the presence of HPV DNA only under nonstringent conditions of hybridization using a mixed probe, and interestingly four of five were laryngeal cancer specimens.

For p53 mutational analysis, four separate PCR reactions (one each for exons 5-8) were performed on DNA from each specimen. PCR products were then subject to SSCP at both room temperature and at $4^{\circ} \mathrm{C}$ (Figure 1). Initially, it seemed that 10 tumor specimens had altered mobility of the PCR-amplified fragments on SSCP. Six specimens had one exon with altered mobility, two had 2 exons with altered mobility, and two had 3 exons with altered mobility for a total of 16 possible mutations. However, after sequencing, four were found to be silent mutations that did not alter the amino acid sequence, and two were sequenced as wild type, despite sequencing at least five clones from each specimen.

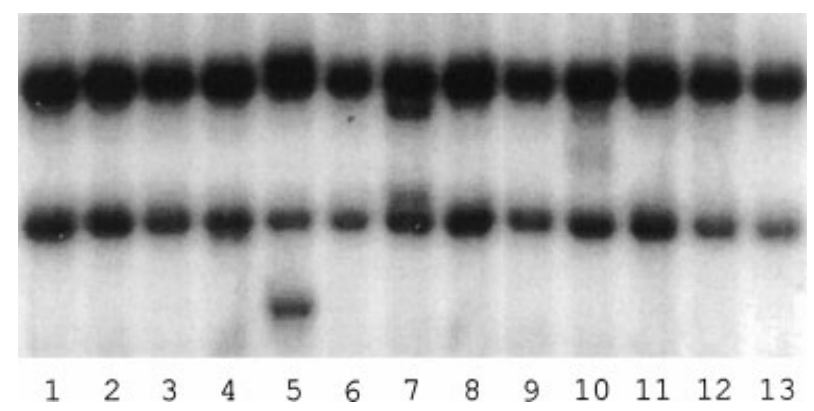

FIGURE 1. Single-strand conformational polymorphism reactions of p53 from multiple SCCHN specimens. Exon 7 was amplified using ${ }^{32} \mathrm{P}$-labeled PCR, denatured and run on nondenaturing MDE gels. Specimens were compared with wild-type p53 banding pattern (lane 1). Samples displayed either a pattern similar to wild type (lanes $2-4,6,8,9,11-13$ ) or an altered banding pattern (lanes 5, 7, and 10). 

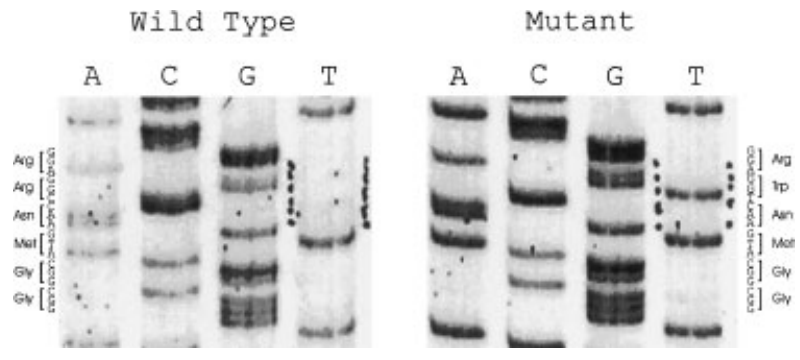

FIGURE 2. Representative DNA sequencing experiment. Exon 7 of the p53 gene has a CGG to TGG transition in codon 284, resulting in an arginine to tryptophan substitution.

Therefore, overall 8 of the $32(25 \%)$ SCCHN specimens exhibited nonsilent p53 mutations. Two specimens had two separate mutations for a total of 10 mutations. After analysis by SSCP and automated sequencing (University of Michigan DNA Sequencing Core), all the 10 mutations discovered were subject to manual sequencing (Figure 2). There was a 100\% correlation between the automated and manual results. When broken down into the types of mutations, there were two transversions, six transitions, and one deletion (Table 1).

The samples were divided into HPV DNA-positive and HPV DNA-negative groups (Table 2). Six of 17 (35\%) of the HPV DNA-negative samples were found to have a nonsilent mutation of the p53 gene as opposed to only 2 of $15(13 \%)$ of the HPV DNA-positive group ( $p=$ 0.229 ; Fisher's exact test, odds ratio .28). Although clearly not statistically significant, these data do suggest the possibility of a potential association between HPV positivity and the presence of wild-type p53. To statistically confirm such an association, a sample of $92 \mathrm{HPV}$-positive tumors and $92 \mathrm{HPV}$-negative tumors (184 total patients) would be required for p53 determination $($ power $=80 \%$; two-sided alpha $=.05)$. Such an association could be observed because of confounding by other risk factors; however, in this study there were no significant differences between HPV DNA-positive and HPV DNA-negative groups in regard to tobacco $(p=.61)$ or alcohol $(p=.86)$ exposure, site of disease $(p=.61)$, or stage of disease $(p=.36)$. There was also no statistically significant association between p53 mutation and the preceding variables ( $p$ value range $=.517$ to .847 )

We have previously reported the results of univariate analyses used to identify factors predictive of survival. ${ }^{18}$ This was repeated to include p53 status as a variable. Among the variables analyzed: HPV status, p53 status, age, smoking history, alcohol exposure, stage and site, HPV $(p=.0264 ; 95 \%$ CI $[0.04,0.88])$ and $\mathrm{p} 53$ status ( $p=.01 ; 95 \%$ CI $[1.36,14.7])$ were statistically significant in univariate log rank analysis (Figures 3 and 4). Patients with HPV-positive tumors had a hazard ratio for death that was .19 of that for patients with HPV-negative tumors. The hazard ratio for death in patients with tumors harboring p53 mutations was 4.48 times that for patients with wild-type p53 tumors. Interestingly, when only p53 wild-type samples were analyzed, there was still a survival advantage for HPV-positive versus HPV-negative patients $(p=.008)$.

Next, we stratified patients into four groups to account for both HPV and p53 status. These included HPV-positive/p53 wild type (100\% survival), HPV-negative/p53 wild type (55\% survival), HPV-positive/p53 mutation (0\% survival), and HPV-negative/p53 mutation (33\% survival) (Table 2). There was a statistically significant survival difference among the four groups $(p=.003)$ (Figure 5). There were 13 patients in the HPV-positive/p53 wild-type group, and all were alive at the completion of the study.

\begin{tabular}{cccll}
\hline & & & Table 1. Characterization of p53 mutation. & \\
\hline Sample & Exon & Codon & Mutation & Amino acid \\
\hline 6 & 6 & 193 & CAT to GAT & Histidine to aspartic acid \\
14 & 7 & 236 & TAG to TAA & Tyrosine to STOP \\
14 & 7 & 237 & ATG to TTG & Methionine to leucine \\
15 & 8 & 273 & CGT to CAT & Arginine to histidine \\
18 & 6 & $187-188$ & Deletion & Glutamine to STOP \\
20 & 5 & 144 & CAG to TAG & Tryptophan to STOP \\
20 & 5 & 146 & TAC to TGC & Tyrosine to cysteine \\
23 & 7 & 236 & TAC to TGC & Glycine to serine \\
25 & 7 & 245 & GGC to AGC & Arginine to tryptophan \\
30 & 7 & 248 & CGG to TGG &
\end{tabular}


Table 2. Stratification of patients by both HPV DNA detection and p53 mutation status.

\begin{tabular}{lcc}
\hline & \multicolumn{2}{c}{ HPV } \\
\cline { 2 - 3 } p53 & Positive & Negative \\
\hline Mutation & 2 & 6 \\
Wild type & 13 & 11 \\
\hline
\end{tabular}

The statistical difference likely results from the survival advantage in this group. In fact, when the HPV-positive/p53 wild-type group is compared with all other patients combined, there is a statistically significant survival difference on log rank test $(p=.001)$. In this small sample the potential of confounding by other risk factors cannot be determined; however, as stated earlier, demographic and disease characteristics seemed to be similar between patients with HPV-positive and HPV-negative tumors.

\section{DISCUSSION}

The most common cancer-related genetic change known among human tumors is the p53 mutation. Among newly diagnosed head and neck cancer cases, $45 \%$ are estimated to contain p53 mutations. ${ }^{15}$ Single-base substitutions account for most mutations, although allelic loss, rear-

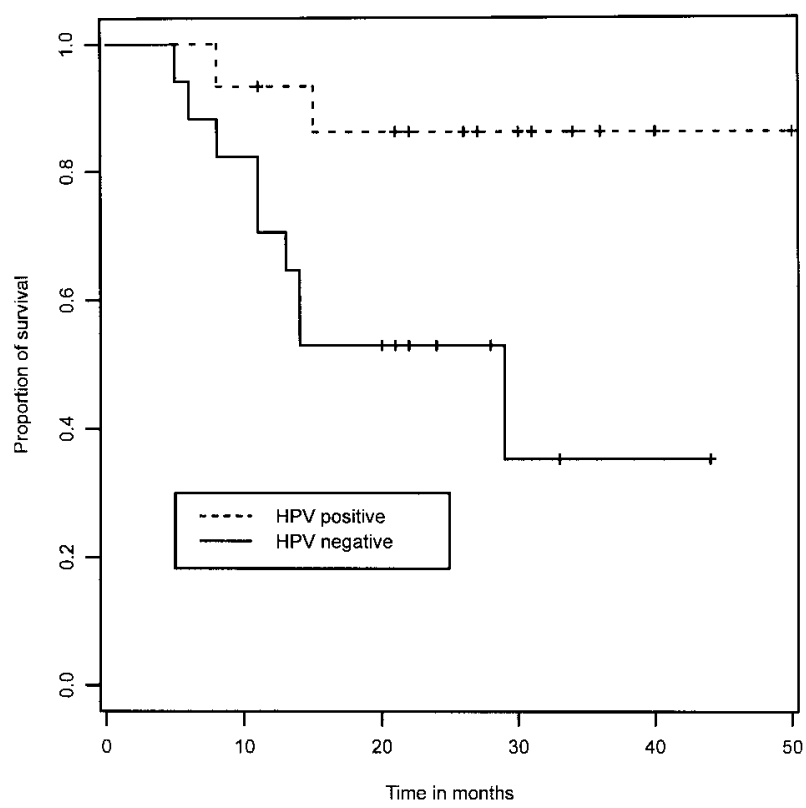

FIGURE 3. Survival curve for patients with HPV-positive versus HPV-negative SCCHN specimens $(p=.0264)$. rangements, and deletions have been detected. ${ }^{24}$ Exons 5-8 comprise the most evolutionary conserved region of p53 in addition to being functionally important as the DNA binding region and binding region for viral antigens. A review found that $98 \%$ of 280 base substitutions reviewed fell within exons $5-8 .^{24}$ It is for this reason that we believed analysis of exons 5-8 would sufficiently detect p53 mutations among our head and neck cancer specimens.

Overall, nonsilent p53 mutations were detected in 8 of $32(25 \%)$ samples. Two samples contained two different mutations for a total of 10 mutations. In addition, four silent mutations (ie, did not alter the amino acid sequence) were detected. This is somewhat less that expected for head and neck cancer in general. Reasons for this may include the fact that our population contains more "young" patients that have not typically been studied in head and neck cancer studies, the fact that a small percentage of mutations may lie outside exons 5-8, or the fact that HPV was detected in 15 of 32 tumor specimens. Regarding types of mutations, transversions have been found to be the predominant type among other tobacco-related tumors, including lung and esophagus. ${ }^{24}$ In non-small cell lung cancer, the predominant mutation is a $\mathrm{G}$ to $\mathrm{T}$ transversion induced by the tobacco carcinogen, benzo-[a]pyrene. We did not find a similar trend among our head and neck cancer specimens, because only 3 of

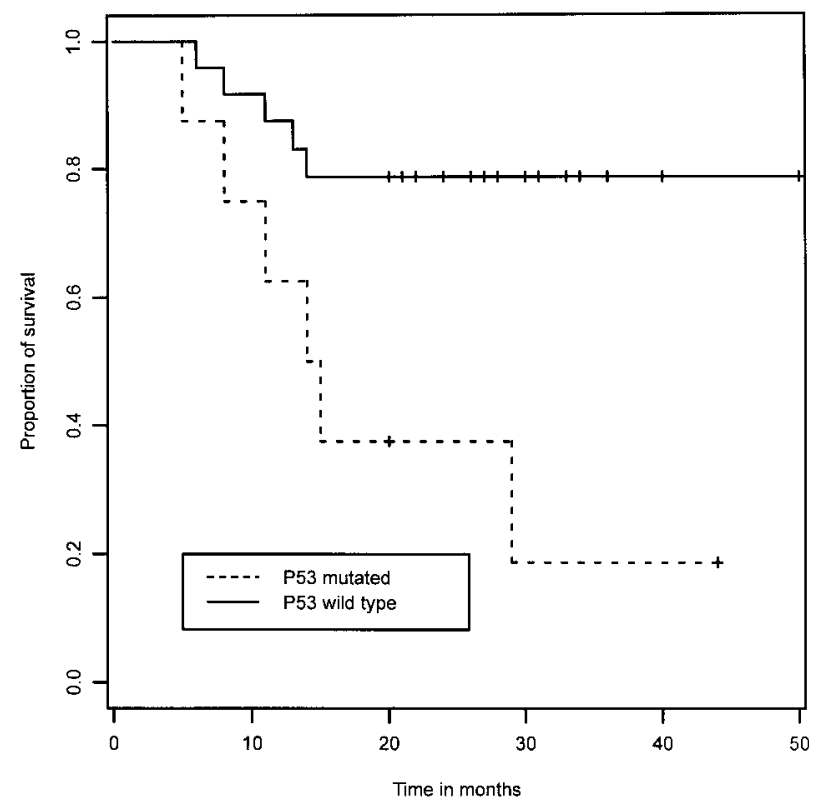

FIGURE 4. Survival curve for patients with p53 wild-type versus p53 mutant SCCHN specimens $(p=.01)$. 


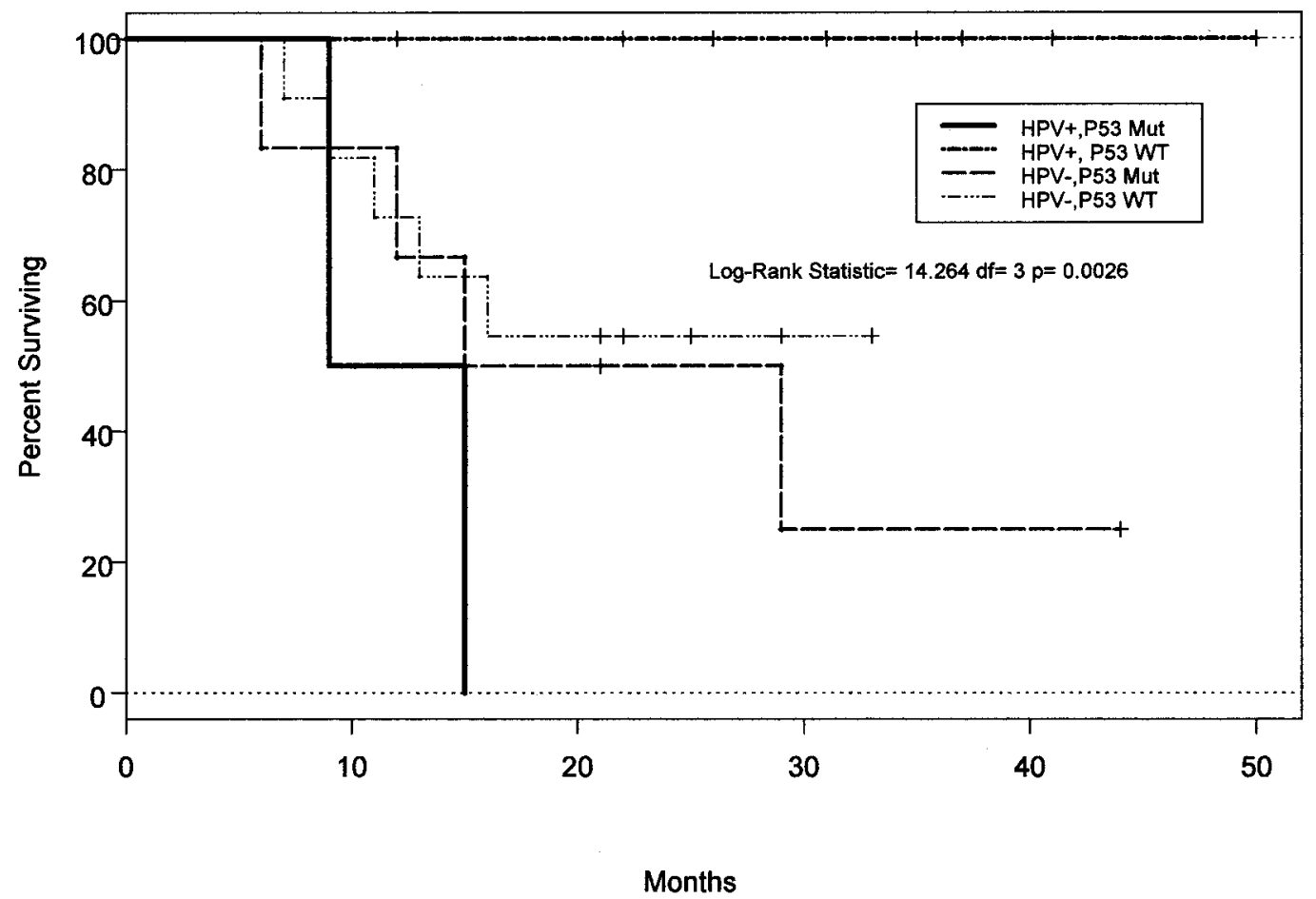

FIGURE 5. Survival curve for patients stratified by both HPV and p53 mutational status $(p=.003)$.

$10(30 \%)$ of the total mutations were transversions. However, larger studies are needed to confirm the most common mutations in SCCHN. We did find that survival was statistically greater in tumors with wild-type p53 compared with tumors with a p53 mutation. This survival disadvantage with a p53 mutation has been previously demonstrated in $\mathrm{SCCHN}^{16}$ and is not unexpected, given p53's tumor-suppressor function.

Many of the clues as to how HPV may contribute to oncogenesis in SCCHN have come from studies on carcinomas of the genital tract. In these tumors, the "high-risk" HPV types, namely types 16 and 18, are thought to be oncogenic because of type-specific differences in the E6 and E7 proteins. ${ }^{13}$ Because the E6 oncogene from high-risk HPV strains has been shown to bind to p53 and promote its degradation, it is possible that the p53 gene may be wild type but is functionally inactivated by HPV. Indeed, it has been shown that HPV-positive cervical cancer cells only rarely contain p53 mutations. ${ }^{17}$

To determine whether this relationship also exists in SCCHN, we analyzed the frequency of p53 gene mutations in the HPV-negative SCCHN samples versus the HPV-positive samples. We found a trend in the relationship between HPV positivity and the presence of a wild-type p53 gene compared with HPV-negative samples. These findings support those of Gillison et $\mathrm{al}^{2}{ }^{2}$ in which $39 \%$ of samples contained p53 mutations, and HPV-positive tumors were less likely to contain p53 mutations. Interestingly, this relationship became statistically significant only when oropharyngeal tumors were analyzed separately. We are unable to draw such site-specific differences given the limitations of sample size. Haraf et $\mathrm{al}^{4}$ also found $18 \%$ of SCCHN specimens to be positive for HPV, but only one of these carried a mutated p53 gene. The inverse relationship may suggest that HPV is able to induce carcinogenesis by means of the effects of its oncoproteins, namely E6 and E7, on important endogenous regulators of the cell cycle. It also suggests that the pathogenesis of SCCHN may be different, depending on whether the tumor contains HPV. Although interruption of normal p53 activity is a final common endpoint, it may be achieved by means of degradation because of the HPV-E6 protein, by means of mutation because of tobacco carcinogens, by means of other less characterized routes, or by means of a combination of factors. However, our data suggest that one p53 insult may be sufficient.

Despite this, HPV infectivity may not be entirely analogous to a functional p53 inactivation. 
One study showed that although HPV-positive cervical cancer cells expressed the E6 protein, endogenous p53 protein was still able to act as a transcriptional activator. p53 levels in these cells were even shown to increase in response to exposure to genotoxic agents as would be expected in cells with functional, wild-type p53. ${ }^{25}$ It may be that the level of E6 protein present is important in determining the activity of p53. It has also been suggested that E6 levels may be elevated early in tumorigenesis, so that inactivation of p53 is an early transient event. ${ }^{25} \mathrm{E} 7$ or other viral functions may then act to carry on the malignant phenotype. Because p53 has multiple cellular roles, it is also possible that E6 may affect apoptotic function rather than transcriptional regulation.

It is interesting that in this study and in a previous study we found survival to be statistically improved when comparing HPV-positive tumors with HPV-negative tumors. Although prior survival studies had contradictory conclusions, the largest study to date has also found a statistically significant improved survival (both overall and disease-free) in HPV-positive SCCHN patients compared with HPV-negative patients. ${ }^{2}$ HPV-positive tumors had $74 \%$ less risk of disease-specific mortality. A second large study of 254 patients with oral SCC found HPV-positive patients to have significantly reduced overall and disease-specific mortality, even though HPVpositive tumors were more advanced in stage. ${ }^{3}$ Haraf et $\mathrm{al}^{4}$ also showed that among stage 4 patients, the most significant predictor of improved survival was HPV positivity.

Reasons for a survival advantage among patients with HPV-positive SCCHN are unclear. As alluded to previously, it is possible that some endogenous p53 protein escapes inactivation by the HPV E6 protein. This would not be as damaging to cell regulation as complete inactivation of $\mathrm{p} 53$ by a mutation. This is supported by the fact that there was $100 \%$ survival in the HPVpositive/p53 wild-type group, and survival was statistically greater than in the other groups. If HPV-positive patients tend to have wild-type p53 genes, this would support improved survival for this group as a whole. In addition, tumors with wild-type p53 status may demonstrate increased radiosensitivity, leading to prolonged survival. However, this remains to be determined in the setting of HPV positivity. One recent study found a statistical survival advantage when comparing
HPV-positive patients who received radiation therapy with those who did not. ${ }^{3}$

Thus, although the numbers are small, this preliminary study supports the notion that HPV and p53 mutational status are prognostic factors in head and neck cancer. There seems to be a survival advantage for HPV-positive patients, in particular those who also retain wild-type p53 status. In addition, we did find a trend toward a lower incidence of p53 mutations among HPVpositive samples, but whether this relationship reaches statistical significance needs to be evaluated in a larger investigation. A major limitation of this analysis is the small sample size, which negated the conduct of a multivariate analysis. Such an analysis would have allowed us to control for other risk factors, including patient and disease characteristics and health behaviors such as smoking and alcohol intake when examining differences in survival among HPV and p53 groups. Although no statistically significant differences in tobacco or alcohol use, site of disease, or stage of disease were detected between HPV groups, the possible influence of each of these factors on the study results could bias the study conclusions. A larger investigation is warranted to confirm our results with a multivariate analysis.

Acknowledgments. We would like to acknowledge Wayne $\mathrm{D}$. Lancaster, $\mathrm{PhD}$, and Lucie Gregoire, $\mathrm{PhD}$, for their knowledge, expertise, and technical support with HPV detection.

\section{REFERENCES}

1. McKaig RG, Baric RS, Olshan AF. Human papillomavirus and head and neck cancer: epidemiology and molecular biology. Head Neck 1998;20:250-265.

2. Gillison ML, Koch WM, Capone RB, et al. Evidence for a causal association between human papillomavirus and a subset of head and neck cancers. JNCI 2000;92:709-720.

3. Schwartz SR, Yueh B, McDougall JK, Daling JR, Schwartz SM. Human papillomavirus infection and survival in oral squamous cell cancer: A population-based study. Otolaryngol Head Neck Surg 2001;125:1-9.

4. Haraf DJ, Nodzenski E, Brachman D, et al. Human papilloma virus and p53 in head and neck cancer: clinical correlates and survival. Clin Cancer Res 1996;2:755-762.

5. Hording U, Nielsen HW, Daugaard S, Albeck H. Human papillomavirus types 11 and 16 detected in nasopharyngeal carcinomas by the polymerase chain reaction. Laryngoscope 1994;104:99-102.

6. Bradford CR, Zacks SE, Androphy EJ, Gregoire L, Lancaster WD, Carey TE. Human papillomavirus DNA sequences in cell lines derived from head and neck squamous cell carcinomas. Otolaryngol Head Neck Surg 1991; 104:303-310.

7. Beck JC, McClatchey KD, Lesperance MM, Esclamado RM, Carey TE, Bradford CR. Human papillomavirus types 
important in progression of inverted papilloma. Otolaryngol Head Neck Surg 1995;113:558-563.

8. Kashima HK, Kutcher M, Kessis T, Levin LS, de Villers EM, Shah K. Human papillomavirus in squamous cell carcinoma, leukoplakia, lichen planus, and clinically normal epithelium of the oral cavity. Ann Otol Rhinol Laryngol 1990;99:55-61.

9. Fouret P, Martin F, Flahault A, Saint-Guily JL. Human papillomavirus infection in the malignant and premalignant head and neck epithelium. Diagn Mol Pathol 1995;4: $122-127$.

10. Paz B, Cook N, Odon-Maryon T, Xie Y, Wilczynski SP. Human papillomavirus (HPV) in head and neck cancer. Cancer 1997;79:595-604.

11. Miller CS, White DK. Human papilloma virus expression in oral mucosa, premalignant conditions, and squamous cell carcinoma. Oral Surg Oral Med Oral Pathol 1996;82:58-68.

12. Steinberg BM, DiLorenzi TP. A possible role for human papilloma virus in head and neck cancer. Cancer Metas Rev 1996;15:91-112.

13. Scheffner M, Werness BA, Huibregtse JM, Levine AJ, Howley PM. The E6 oncoprotein encoded by human papillomavirus types 16 and 18 promotes the degradation of p53. Cell 1990;63:1129-1136.

14. Dyson N, Howley PM, Munger K, Harlow E. The human papillomavirus-16 E7 oncoprotein is able to bind to the retinoblastoma gene product. Science 1989;243: 934-936.

15. Harris CC. Structure and function of the p53 tumor suppressor gene: clues for rational cancer therapeutic strategies. JNCI 1996;88:1442-1454.

16. Bradford CR, Zhu S, Poore J, et al. p53 mutation as a prognostic marker in advanced laryngeal carcinoma. Arch Otolaryngol Head Neck Surg 1997;123:605-609.
17. Scheffner M, Munger K, Byrne JC, Howley PM. The state of the p53 and retinoblastoma genes in human cervical carcinoma cell lines. Proc Natl Acad Sci 1991;88:55235527.

18. Sisk EA, Bradford CR, Jacob A, et al. Human papillomavirus infection in "young" versus "old" patients with squamous cell carcinoma of the head and neck. Head Neck 2000;22:649-657.

19. Ting Y, Manos MM. Detection and typing of genital human papillomaviruses. In: Innis A, Gelfand DG, Sninsky JJ, White TJ, editors. PCR Protocols: A Guide to Methods and Applications. San Diego, CA: Academic Press; 1990. p $356-367$.

20. Gregoire L, Arella M, Campione-Piccardo H, Lancaster WD. Amplification of human papillomavirus DNA sequences by using conserved primers. J Clin Microbiol 1989;27:2660-2665.

21. Shamanin V, Delius H, deVillers EM. Development of a broad spectrum PCR assay for papillomaviruses and its application in screening lung cancer biopsies. J Gen Virol 1994;75:1149-1156.

22. Shibata DK, Arnheim N, Martin WJ. Detection of human papilloma virus in paraffin-embedded tissue using the polymerase chain reaction. J Exp Med 1988;167: $225-230$.

23. Fujita M, Inoue M, Tanizawa O, Iwamoto S, Enomoto T. Alterations of the p53 gene in human primary cervical carcinoma with and without human papillomavirus infection. Cancer Res 1992;52:5323-5328.

24. Hollstein M, Sidransky D, Volgelstein B, Harris CC. p53 mutations in human cancers. Science 1991;253:49-53.

25. Butz K, Shahabeddin L, Geisen C, Spitkovsky D, Ullmann A, Hoppe-Seyler F. Functional p53 protein in human papillomavirus-positive cancer cells. Oncogene 1995;10: 927-936. 